\title{
Corrigendum
}

\section{Corrigendum to "Effect of Plant Spacing on Yield and Yield Components of Tomato (Solanum lycopersicum L.) in Shewarobit, Central Ethiopia"}

\author{
Getachew Amare (iD) ${ }^{1}$ and Hailay Gebremedhin ${ }^{2}{ }^{2}$ \\ ${ }^{1}$ Department of Horticulture, College of Agriculture and Natural Resources Sciences, Debre Berhan University, P.O. Box: 445, \\ Debre Berhan, Ethiopia \\ ${ }^{2}$ Department of Horticulture, College of Agriculture and Environmental Sciences, Adigirat University, P.O. Box: 50, \\ Adigirat, Ethiopia
}

Correspondence should be addressed to Getachew Amare; getchamare38@gmail.com

Received 10 November 2020; Accepted 10 November 2020; Published 23 November 2020

Copyright (c) 2020 Getachew Amare and Hailay Gebremedhin. This is an open access article distributed under the Creative Commons Attribution License, which permits unrestricted use, distribution, and reproduction in any medium, provided the original work is properly cited.

In the article titled "Effect of Plant Spacing on Yield and Yield Components of Tomato (Solanum lycopersicum L.) in Shewarobit, Central Ethiopia" [1], author Hailay Gebremedhin was affiliated to "Department of Horticulture, College of Agriculture and Environmental Sciences, Debre Berhan University, P.O. Box: 50, Debre Berhan, Ethiopia," which is incorrect. The correct affiliations for this author are as follows:

${ }^{2}$ Department of Horticulture, College of Agriculture and Environmental Sciences, Adigirat University, P.O. Box: 50, Adigirat, Ethiopia.

The corrected list of affiliations is shown in the author information above.

\section{Reference}

[1] G. Amare and H. Gebremedhin, "Effect of plant spacing on yield and yield components of tomato (Solanum lycopersicum L.) in Shewarobit, Central Ethiopia," Scientifica, vol. 2020, Article ID 8357237, 6 pages, 2020. 